\title{
Telicidade e determinantes plurais indefinidos no espanhol da Espanha
}

\section{Telicity and indefinite plural determiners in Spanish spoken in Spain}

\author{
Jean Carlos da Silva GOMES* \\ Adriana Leitão MARTINS**
}

\begin{abstract}
RESUMO: A telicidade é uma noção aspectual semântica entendida como o ponto final inerente e linguisticamente marcado de uma situação. Segundo Moure (1990), a presença de determinantes como "el/un" direciona a uma leitura télica da sentença, enquanto a ausência de determinantes direciona a uma leitura atélica. No entanto, não se sabe a qual leitura os determinantes plurais podem levar. Determinantes plurais como "unos/algunos" podem ser interpretados como um tipo de determinante plural indefinido, que é o foco deste trabalho. De acordo com De Miguel (1999), esses determinantes direcionam a uma leitura atélica da sentença, ao passo que, segundo Rothstein (2008), eles direcionam a uma leitura télica. No espanhol, uma das formas de evidenciar o valor aspectual de telicidade é por meio de uma partícula conhecida como se télico. Investigou-se, neste trabalho, a compatibilidade dessa partícula aspectual com verbos cujos complementos são introduzidos por determinantes plurais indefinidos na variedade do espanhol da Espanha conhecida como castelhano setentrional

ABSTRACT: Telicity is a semantic aspectual notion understood as the inherent endpoint of a situation, whichis linguistically expressed. According to Moure (1990), the presence of determiners as "el/un" leads to a telic reading of the sentence, while the absence of determiners leads to an atelic reading. However, it is unknown to which reading plural determiners can lead. Plural determiners such as "unos/algunos" can be interpreted as a kind of indefinite plural determiner, which is the object of study of this research. According to De Miguel (1999), these determiners lead to an atelic reading of the sentence, whereas, according to Rothstein (2008), they lead to a telic reading. In Spanish, one of the ways to highlight the value of telicity is by means of a particle known as telic se. It was investigated, in this paper, the compatibility of this aspectual particle with verbs whose complements are introduced by indefinite plural determiners in a variety of Spanish spoken in Spain known as peninsular northern Castilian. The results indicated that this combination is possible. Thus, it was discussed that the presence of this
\end{abstract}

\footnotetext{
* Mestrando em Linguística (UFRJ). ORCID: https://orcid.org/0000-0002-4022-0580. gomes.jean@outlook.com

** Professora associada (UFRJ). ORCID: $\quad$ http://orcid.org/0000-0003-0510-2586.
}


peninsular. Os resultados indicaram que essa combinação é possível. Dessa forma, discutiu-se que a presença desse tipo de determinante direciona a uma leitura télica da sentença e que essa combinação sugere que o valor aspectual télico de uma sentença não depende da presença de uma medida precisa para a delimitação do complemento.

PALAVRAS-CHAVE: Telicidade. Determinantes plurais indefinidos. Espanhol. type of determiner leads to a telic reading of the sentence and that this combination suggests that the telic aspectual value of a sentence does not depend on the presence of a precise measure for the complement delimitation.

\section{Introdução}

Telicidade é entendida como uma noção aspectual semântica que se refere ao ponto final inerente de uma situação (COMRIE, 1976; DAHL, 1977; DECLERCK, 1979; SLABAKOVA, 2000; BERTINETTO, 2001; BASSO, 2007). Assim, uma sentença que apresenta esse ponto final expresso linguisticamente é considerada télica, enquanto uma que não o possui é considerada atélica.

Segundo Moure (1990), no espanhol, complementos introduzidos por determinantes singulares como "el/un" direcionam a uma leitura télica e complementos não introduzidos por determinantes direcionam a uma leitura atélica. Por outro lado, a autora destaca que não se sabe a qual leitura complementos iniciados por determinantes plurais poderiam direcionar. Entendemos que determinantes plurais como "algunos(as)" e "unos(as)" podem ser considerados determinantes plurais indefinidos, sendo esses o foco de estudo desta pesquisa ${ }^{1}$.

Para De Miguel (1999), uma das formas de realizar a telicidade no espanhol é por meio do se télico combinado a um verbo cujo complemento direto seja iniciado por

\footnotetext{
${ }^{1}$ Ao restringirmos nosso estudo sobre a telicidade às sentenças em que os complementos verbais são introduzidos por determinantes plurais, destacamos que, consequentemente, voltamos nossa análise para complementos cujos núcleos dos sintagmas nominais são nomes contáveis, não massivos.
} 
um determinante que delimite o evento. Assumindo que o se télico seja considerado um marcador evidente de telicidade (LOURENÇONI, 2017), neste estudo, ele é utilizado como o instrumento linguístico que possibilita investigar se complementos introduzidos por determinantes plurais indefinidos podem delimitar o evento, direcionando, portanto, a uma leitura télica.

O objetivo geral deste trabalho é contribuir para o entendimento dos fatores que afetam a telicidade do evento. O objetivo específico é investigar a compatibilidade do se télico com verbos cujos complementos sejam introduzidos por determinantes plurais indefinidos na variedade do espanhol da Espanha conhecida como castelhano setentrional peninsular. Para isso, baseamo-nos na hipótese de que o se télico não se combina com complementos verbais introduzidos por determinantes plurais indefinidos no castelhano setentrional peninsular.

Este artigo está dividido da seguinte maneira: na primeira seção, discorremos sobre o valor aspectual de telicidade; na segunda seção, apresentamos a metodologia adotada neste trabalho; na terceira seção, apresentamos os resultados obtidos; na quarta seção, analisamos e discutimos os resultados; e, por fim, apresentamos as considerações finais deste estudo.

\section{$2 \mathrm{O}$ valor aspectual de telicidade}

De acordo com Comrie (1976), um dos valores aspectuais que podem ser depreendidos de uma sentença é o inerente aos itens lexicais que a compõem. Tal aspecto, conhecido como semântico ${ }^{2}$, pode referir-se, portanto, a certos valores semânticos inerentes à raiz verbal, aos argumentos e/ou aos adjuntos presentes nas sentenças, independentemente de qualquer marcação morfológica. Em relação a esse

\footnotetext{
2 Também conhecido como "aspecto lexical” (DE MIGUEL, 1999), “tipo de situação" (SMITH, 1991) ou "aktionsart" (SANZ; LAKA, 2002). Neste trabalho, optamos por utilizar a nomenclatura "aspecto semântico".
} 
aspecto, Comrie (1976) postulou a existência de três oposições aspectuais semânticas ${ }^{3}$, são elas: estatividade versus dinamicidade, pontualidade versus duratividade e telicidade versus atelicidade, sendo essa última o objeto deste estudo.

A palavra telicidade vem do termo grego télos, que significa "objetivo", fim". Dessa forma, a noção de telicidade está relacionada à presença de um ponto final que impede que uma determinada situação continue para além dele. Segundo Comrie (1976), um evento télico é aquele que leva a um ponto final delimitado linguisticamente, como no exemplo em (1), enquanto um evento atélico não possui esse ponto final, como observado em (2).

(1) Juan bebió un vaso de zumo.

'João bebeu um copo de suco.'

(2) Juan bebió vasos de zumo. 'João bebeu copos de suco.'

Ao observamos os exemplos acima, podemos perceber que a sentença presente em (1) é télica, pois o complemento "un vaso de zumo" delimita o ponto final da situação, de modo que a ação não pode continuar para além dele. Por outro lado, a sentença em (2) é atélica, pois não apresenta um ponto final delimitado pelo complemento "vasos de zumo" ${ }^{4}$.

\footnotetext{
3 Comrie (1976) discorreu sobre noções aspectuais semânticas sem abordar a noção de traços linguísticos. Smith (1991), por sua vez, ao propor uma classificação dos tipos de verbo, adotou uma proposta de traços relacionados às noções aspectuais propostas por Comrie (1976). Dessa forma, a autora postulou a existência de três traços aspectuais semânticos [ \pm estático], [ \pm durativo] e [ \pm télico]. Adotamos aqui, com base em Wachowicz (2008), que os verbos podem carregar traços [ \pm estático] e [ \pm durativo] e que a telicidade é um valor aspectual depreendido por meio de diferentes constituintes da sentença.

${ }^{4}$ Vale destacar que diversos testes foram propostos na literatura com a intenção de verificar a delimitação do ponto final da situação expressa na sentença, tais como a prova de interrupção (GAREY, 1975), a prova de inclusão (COMRIE, 1976) e a prova de compatibilidade com advérbios durativos (DECLERCK, 1979).
} 
A análise do tipo de complemento presente no predicado é considerada relevante para o entendimento dos valores aspectuais semânticos depreendidos em uma sentença. Bertinetto (2001), por exemplo, apresenta uma extensa discussão acerca da importância do objeto direto na classificação dos verbos quanto aos tipos propostos por Vendler (1967).

De acordo com Wachowicz (2008), a telicidade é um fenômeno externo ao verbo, estando presente no VP, uma vez que depende de outros elementos contidos na sentença, como a quantificação do complemento ou a presença de sintagmas preposicionais que indicam o término do evento. Na mesma direção, Freitag (2011) destaca que o valor aspectual de telicidade é depreendido com base em todo o VP, sendo decorrente da relação entre o aspecto inerente ao verbo, o morfema gramatical verbal $^{5}$, os adjuntos adverbiais e outros constituintes da sentença. A essa contribuição de diferentes elementos que compõem a sentença em seu valor aspectual, atribui-se o termo “composicionalidade aspectual” (VERKUYL, 2002; CELERI, 2008).

Na intenção de compreender os fatores que auxiliam na composição aspectual dos predicados, neste trabalho, buscamos investigar a contribuição que certos determinantes presentes no complemento verbal têm na quantificação necessária para que um evento seja considerado télico.

Sobre essa contribuição, Moure (1990), ao analisar dados do espanhol, apresentou uma relação entre o que a autora chama de "grau de definição do complemento" e a leitura télica/atélica da sentença, como podemos ver na Figura 1 abaixo:

\footnotetext{
${ }^{5}$ Comumente, assume-se que o morfema gramatical verbal veicula aspecto gramatical (COMRIE, 1976; SMITH, 1991). Ainda que as noções de aspecto semântico - aí incluído o valor de telicidade - e gramatical sejam distintas, estudos como os de Castilho (2003), Wachowicz (2003), Lessa (2007), Freitag (2011) e Coan, Freitag e Pontes (2013), dentre outros, demonstram que há uma forte relação entre essas categorias.
} 
Figura 1 -- Relação entre o grau de definição do complemento e o valor aspectual télico no espanhol.

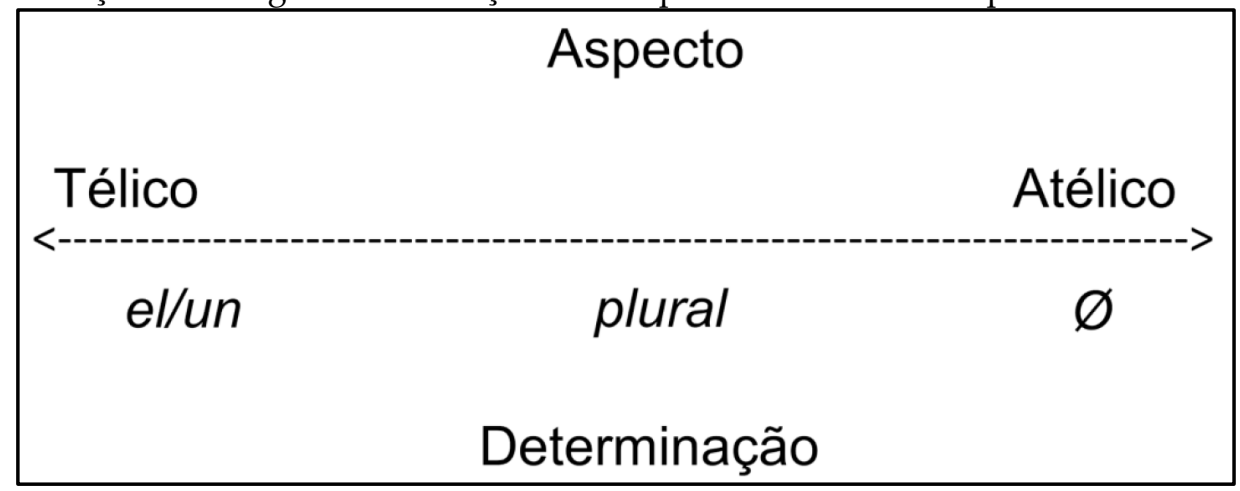

Fonte: Moure (1990, p. 364).

De acordo com essa proposta, determinantes singulares capazes de conferir uma quantificação exata ao seu complemento nominal, como el/un, remetem a uma leitura de valor aspectual télico da sentença, como no exemplo em (3). Por outro lado, a ausência de determinante no complemento verbal direciona a uma leitura atélica da sentença, como em (4). No entanto, pelo exame da Figura 1 extraída de Moure (1990), não se sabe a que leitura levam os determinantes plurais, por exemplo em (5).

(3) Pedro comió la/una manzana.

'Pedro comeu a/uma maçã.'

(4) Pedro comió manzanas.

'Pedro comeu maçãs.'

(5) Pedro comió unas/algunas/muchas/varias manzanas.

'Pedro comeu umas/algumas/muitas/várias maçãs.'

Entendemos aqui que determinantes como unos(as) / algunos(as) / muchos(as) / varios(as) podem ser considerados determinantes plurais indefinidos, pois não são capazes de conferir uma quantificação precisa ao complemento. Neste estudo, voltamos nossa análise a esses determinantes.

Verkuyl (2002) afirma que objetos diretos com quantificação genérica ou que contenham nomes massivos fazem com que a sentença seja atélica. Por outro lado, para Rothstein (2008), o valor aspectual télico do VP pode ser conferido por um objeto direto que contenha uma expressão de quantidade ainda que essa não revele com precisão a 
quantidade do que está sendo medido. Dessa forma, ao analisar dados do inglês, Rothstein (2008) argumentou que determinantes plurais indefinidos podem direcionar a uma leitura télica da sentença porque são capazes de conferir a medida necessária para delimitar o VP.

Há, portanto, uma divergência na literatura quanto à interpretação dos determinantes plurais indefinidos no tocante ao valor aspectual de telicidade conferido à sentença. Neste trabalho, buscamos investigar tal questionamento com base em dados do espanhol, uma vez que, nessa língua, há recursos linguísticos capazes de evidenciar o valor aspectual de telicidade de uma sentença. Tais recursos linguísticos são apresentados na próxima seção.

\section{Realização linguística de telicidade no espanhol}

A noção aspectual de telicidade pode ser realizada de diferentes formas nas línguas. No espanhol, segundo De Miguel (1999), é possível realizá-la linguisticamente por meio de três formas. A primeira delas é por meio de um complemento direto determinado ${ }^{6}$, aquele que é capaz de conferir um limite ao evento, como exemplificado em (6). A segunda é por meio de um sintagma preposicional delimitador, como no exemplo em (7). A terceira é por meio de uma partícula se, conhecida como se télico ${ }^{7}$, combinada a um verbo cujo complemento direto seja determinado, como no exemplo em (8).

(6) Juan comió una manzana.

'João comeu uma maçã'.

\footnotetext{
6 Slabakova (2000) e Lourençoni (2014) utilizam a nomenclatura "complemento de cardinalidade especificada" para referir-se ao que De Miguel (1999) conceitua como "complemento direto determinado".

${ }^{7}$ Neste trabalho, adotamos a nomenclatura se télico, com base em De Miguel (1999) e em Martins, Gomes e Lourençoni (2017). No entanto, na literatura, são utilizadas também outras nomenclaturas como partícula se (GOMES, 2017), se aspectual (LOPEZ, 2002), clítico télico (SANZ; LAKA, 2002) e operador aspectual se (LOURENÇONI, 2017).
} 
(7) Juan nadó hasta el fin de la piscina.

'João nadou até o fim da piscina.'

(8) Juan se comió una manzana.

'João comeu uma maçã.'

O se télico é uma partícula opcional no espanhol. Portanto, não se pode afirmar que seja o único responsável por conferir um limite para o evento, visto que o complemento que figura em sentenças com essa partícula já delimita o evento, conferindo-lhe um ponto final inerente. Além disso, como visto na seção anterior, são diversos os fatores que contribuem para a leitura télica de uma sentença. Porém, uma vez que essa partícula esteja presente na sentença, ela ratifica a sua telicidade (LOURENÇONI, 2017).

O se télico varia de acordo com número e com pessoa gramaticais do sujeito da oração na qual está inserido. Assim, pode assumir as seguintes formas: me, te, se, nos e $o s^{8}$. De acordo com De Miguel (1999), essa partícula só pode figurar em sentenças que contenham verbos transitivos, como no exemplo em (8), e inacusativos, como na sentença em (9). Segundo Sanz (2000), o uso do se télico é mais frequente quando associado a verbos de ingestão ${ }^{9}$, como no exemplo em (8), sendo considerado esse, um fator que favorece o uso dessa partícula.

(9) El libro se ha caído del estante.

'O livro caiu da estante.' 10

Outro contexto favorecedor para o uso do se télico, segundo De Miguel \& Lagunilla (2000), é a utilização de verbos com morfologia perfectiva, aquela que

\footnotetext{
${ }^{8}$ Neste artigo, ao fazer referência ao "se télico", remetemo-nos a qualquer uma dessas formas que essa partícula pode assumir.

${ }^{9}$ Verbos de ingestão são aqueles cujo significado remete à ideia de que o sujeito toma algo para si mesmo (ARCE ARCENALES, 1989 apud LÓPEZ, 2002), como comer, beber, tomar etc.

${ }^{10}$ Exemplo extraído de De Miguel (1999, p. 2996).
} 
destaca a visualização de um evento como um todo sem fazer distinção entre as diferentes fases que o compõem (COMRIE, 1976), como no exemplo em (10).

Segundo Comrie (1976), Smith (1991), Slabakova (2000), Sanz \& Laka (2002), Wachowicz (2008) e Lourençoni (2017), o valor aspectual télico é incompatível com o traço [+estático]. Desse modo, o se télico não pode figurar em sentenças que contenham verbos que carreguem esse traço. $\mathrm{O}$ exemplo em (10) retrata uma sentença agramatical, pois o se télico aparece combinado a um verbo de estado.

(10) *Rosa se odia al professor de español.

'Rosa odeia o professor de espanhol.'

Por outro lado, com relação à compatibilidade do valor aspectual télico de uma sentença como traço [-durativo] dos verbos, parece não haver um consenso na literatura. De acordo com Smith (1991) e com Slabakova (2000), verbos que carreguem o traço [-durativo], tidos como pontuais, seriam compatíveis com sentenças télicas. Por outro lado, segundo Comrie (1976), Sanz e Laka (2002), Wachowicz (2008) e Lourençoni (2017), tais verbos seriam incompatíveis com sentenças télicas. No tocante especificamente ao se télico, Sanz \& Laka (2000) e Lourençoni (2017) destacam que não seria possível combiná-lo a verbos que carreguem esse traço, o que explicaria a agramaticalidade de sentenças como a apresentada em (11).

(11) *Rosa se cruzó la línea de meta.

'Rosa cruzou a linha de chegada.'

Os contextos semânticos e morfossintáticos que ensejam o uso do se télico em diferentes variedades do espanhol ainda têm sido investigados na literatura (cf. LOURENÇONI; MARTINS, 2016). Na seção anterior, apresentamos a contribuição de determinantes plurais indefinidos para o valor de telicidade da sentença nas línguas, que é discutível na literatura. Nesta, examinamos o se télico quando está presente em 
sentenças do espanhol que contenham verbos cujos complementos sejam introduzidos por esses determinantes, contribuindo, assim, para a revisão da literatura acerca da compatibilidade entre o se télico e os determinantes plurais indefinidos.

Segundo De Miguel (1999), o se télico não pode se combinar a verbos cujos complementos sejam introduzidos por determinantes plurais indefinidos, uma vez que, para essa autora, não são capazes de conferir um limite ao evento. Logo, para ela, uma sentença como a apresentada em (12) seria considerada agramatical no espanhol.

(12) *María se comió algunas manzanas

'Maria comeu algumas maçãs.'

Por outro lado, Suárez-Cepeda (2005), ao discorrer sobre contextos em que o se télico pode figurar, acrescenta as sentenças que contenham verbos cujos complementos são introduzidos por determinantes plurais indefinidos, como no exemplo em (13). A autora não apresenta um embate teórico sobre o valor de telicidade atribuído por tais determinantes, afirmando apenas que o que licencia o uso dessa partícula aspectual nesses contextos está relacionado ao fato de que o objeto que delimita a sentença é afetado pelo evento.

(13) Pedro se tomó algunos/unos vinos.

'Pedro tomou alguns/uns vinhos.' ${ }^{11}$

Neste trabalho, buscamos investigar a possibilidade de combinação entre o se télico e os verbos cujos complementos sejam introduzidos por determinantes plurais indefinidos. Não havendo compatibilidade entre eles, será possível afirmar que esses determinantes direcionam a uma leitura atélica da sentença, como proposto por De Miguel (1999). Porém, caso sejam compatíveis, pode-se advogar em favor da proposta

\footnotetext{
${ }^{11}$ Exemplo extraído de Suárez-Cepeda (2005, p. 279).
} 
de Suárez-Cepeda (2005), na qual se defende que tal combinação é possível no espanhol, e a proposta de Rothstein (2008), na qual se afirma que esses determinantes direcionam a uma leitura télica da sentença.

Colocamos à prova a hipótese, baseada em De Miguel (1999), de que o se télico não se combina com complementos verbais introduzidos por determinantes plurais indefinidos no castelhano setentrional peninsular.

\section{Metodologia}

A metodologia deste trabalho consistiu na aplicação de um teste linguístico e na análise de dados de fala espontânea, coletados de corpora do espanhol. O perfil geral dos participantes pode ser descrito da seguinte forma: falantes nativos do espanhol da Espanha com idade entre 20 e 55 anos e ensino superior completo ou incompleto.

Mais especificamente, todos eram falantes da variedade conhecida como castelhano setentrional peninsular, que corresponde à variedade de espanhol empregada no centro e no norte da Espanha, área que abrange desde Cantábria, pelo norte, até Mancha, no sul, e todas as comunidades autônomas de Castela \& Leão e de Madri, exceto zonas ocidentais de Leão, de Samora e de Salamanca (PATO, 2004; MORENO-FERNÁNDEZ; ROTH, 2007).

\subsection{Teste linguístico}

A fim de investigar se a combinação estudada é possível no castelhano setentrional peninsular, foi aplicado um teste de julgamento de gramaticalidade comentado a dez falantes com o perfil delimitado para o estudo. $\mathrm{O}$ experimento foi aplicado por meio de um formulário Google.

O teste estava composto de 12 sentenças, sendo quatro alvo e oito distratoras. As sentenças alvo continham o se télico associado a um verbo cujo complemento era introduzido por um determinante plural indefinido, como no exemplo em (14). 
(14) María se bebió unos vasos de agua.

'Maria bebeu uns copos de água.'

Em todos os casos, foram utilizados verbos transitivos que apresentavam morfologia perfectiva e que eram classificados como verbos de ingestão, uma vez que esses fatores favorecem a presença do se télico, como descrito na seção 3.

As sentenças distratoras, por sua vez, eram ora gramaticais, como no exemplo em (15), ora agramaticais. As agramaticais caracterizavam-se pela ausência do determinante no sujeito, como no exemplo em (16), ou pela ausência de complemento em verbos transitivos, como no exemplo em (17).

(15) María escribió cartas.

'Maria escreveu cartas.'

(16) *Cocinero hizo pollo asado.

'Cozinheiro fez frango assado.'

(17) *El hombre necesitó.

'O homem precisou.'

A tarefa solicitada era a de que os informantes julgassem as sentenças como naturais ou como estranhas. Caso as considerassem naturais, deveriam indicar com um "OK". Se as julgassem como estranhas, deveriam fazer os ajustes necessários para torná-las naturais.

\subsection{Corpora de fala espontânea}

Diferentemente do teste linguístico, que visava investigar se a combinação estudada é possível no castelhano setentrional peninsular, a análise empreendida nesta segunda fase da pesquisa foi realizada com o objetivo de avaliar se seu uso é produtivo na fala espontânea. 
Para tanto, foram analisadas 3 horas e 35 minutos de fala espontânea pertencente ao Corpus del proyecto para el estudio sociolingüístico del español de España y de América (PRESEEA, 2014) ${ }^{12}$, desenvolvido na Universidad de Alcalá. Mais especificamente, o recorte feito foi o de três entrevistas que continham, cada uma, as falas de um entrevistador e de um entrevistado.

Esse corpus permite uma seleção do perfil dos informantes quanto aos seguintes parâmetros: cidade de origem, sexo, idade e escolaridade. Assim, selecionamos dados de indivíduos da cidade de Madri com idade entre 20 e 54 anos e com ensino superior completo. Não foram feitas restrições quanto ao sexo do informante.

Também foram analisadas 3 horas e 15 minutos de dados de fala espontânea pertencente ao corpus C-Oral ${ }^{13}$. Nesse, além de poder delimitar o perfil dos informantes segundo os parâmetros discriminados acima, era possível acessar a informação acerca da profissão dos informantes. Além disso, o corpus C-Oral permite a escolha entre dados de discurso formal e informal.

O perfil selecionado foi semelhante ao do outro grupo, uma vez que foram analisados dados de indivíduos da cidade de Madri com idade entre 20 e 50 anos e com ensino superior completo. Todos os dados foram retirados do discurso informal e não foram estabelecidas restrições quanto ao sexo e quanto à profissão do informante.

Em ambos os corpora, selecionamos, nos recortes feitos, todas as ocorrências de complementos verbais introduzidos pelos determinantes plurais indefinidos unos(as), algunos(as), muchos(as), varios(as). Nessas ocorrências, buscamos verificar se o se télico aparecia combinado aos verbos que continham esses complementos.

12 Este corpus está disponibilizado em uma plataforma online de livre acesso no link http://preseea.linguas.net/

${ }^{13}$ Trata-se de um material composto de dados de fala de línguas românicas europeias. Não se encontra disponível em plataforma online. 


\section{Resultados}

\subsection{Resultados do teste linguístico}

O teste linguístico tinha por objetivo avaliar a aceitação dos falantes quanto a enunciados formados pela combinação entre o se télico e um verbo cujo complemento fosse introduzido por um determinante plural indefinido.

Em 95\% das sentenças-alvo, que continham invariavelmente o se télico associado a um verbo com complemento introduzido por determinante plural indefinido, os indivíduos não fizeram alterações nas sentenças, considerando gramatical a construção analisada. Apenas em 5\% das sentenças-alvo houve alteração de um determinante plural indefinido por um determinante singular. Mais especificamente, esses 5\% se referem às alterações feitas por um único participante em apenas duas das sentenças-alvo do teste.

Nesse caso, o participante alterou "María se bebió unos vasos de agua" por "María se bebió un vaso de agua" e "Leticia se fumó algunos cigarros" por "Leticia se fumó un cigarro" ${ }^{14}$. No Gráfico 1, a seguir, é possível verificar um resumo da avaliação realizada pelos participantes.

Gráfico 1 - Resultados do teste de julgamento de gramaticalidade comentado.

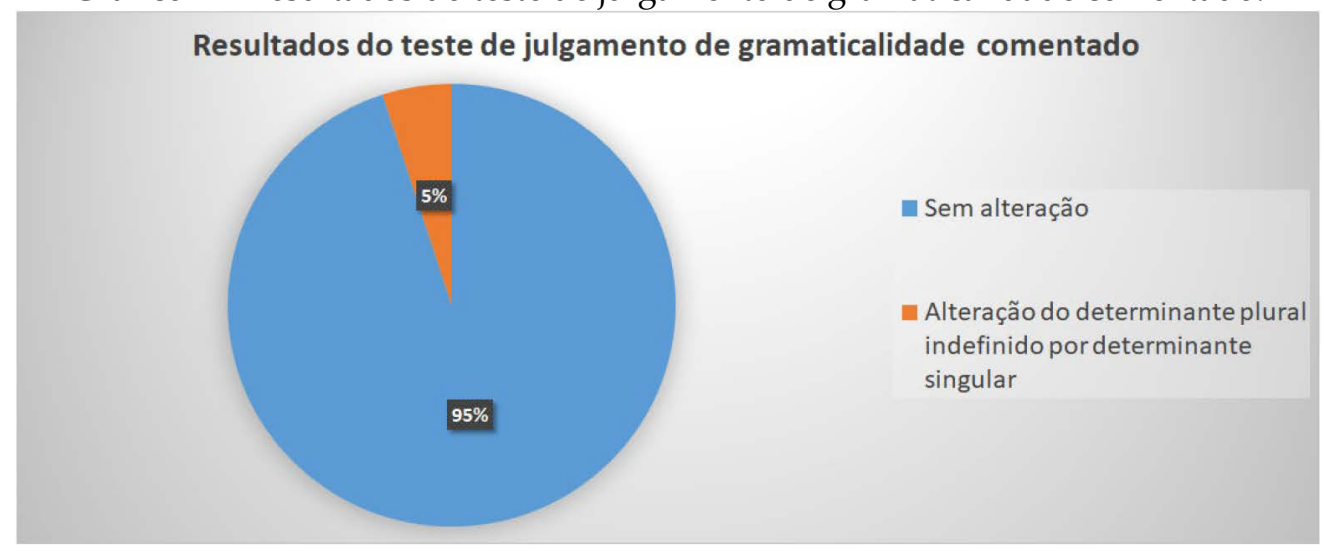

Fonte: elaborado pelos autores.

\footnotetext{
${ }^{14}$ A tradução para as sentenças apresentadas nesse parágrafo são, respectivamente: "Maria bebeu uns copos de água", "Maria bebeu um copo de água", "Letícia fumou uns charutos" e "Letícia fumou um charuto".
} 


\subsection{Análise de fala espontânea}

Em relação aos dados de fala espontânea coletados no PRESEEA, foram encontradas 50 ocorrências de complementos verbais introduzidos por determinantes plurais indefinidos. Vinte e sete deles foram introduzidos pelos determinantes unos(as) (54\%), como no exemplo em (18), 11 por muchos(as) (44\%), como podemos ver em (19), 1 por algunos(as) (2\%), por exemplo em (20), e nenhum por varios(as).

(18) Tiene unas aceras muy grandes.

'Tem umas calçadas muito grandes.'

(19) El alcalde ha puesto muchos árboles.

'O prefeito colocou muitas árvores.'

(20) Hay algunos profesores que han sido estupendos.

'Há alguns professores que foram ótimos.'

Não foi encontrada nenhuma ocorrência de se télico combinado a verbos cujos complementos tenham sido introduzidos por determinantes plurais indefinidos. Além disso, destacamos que não foram encontradas ocorrências desse tipo de determinante em complementos de verbos de ingestão, aqueles que poderiam favorecer o uso do se télico.

Uma vez que não foram encontradas ocorrências do se télico em sentenças que continham o complemento verbal introduzido por determinantes plurais indefinidos, interpretamos que a inexistência dessa partícula nos dados pode ter se dado em função dos tipos de verbos e não do determinante presente nos seus complementos. Por isso, examinamos os traços semânticos aspectuais de estatividade e de duratividade presentes nos verbos das sentenças analisadas. Essa descrição será exposta abaixo e a análise desses dados será apresentada na seção de discussão deste artigo.

Com relação à estatividade, destacamos que 38 verbos das sentenças analisadas apresentavam o traço [+estático] (76\%), enquanto 12 deles apresentavam o traço [estático] (24\%), como podemos ver no Gráfico 2. 
Gráfico 2 - Traço de estatividade nos verbos das sentenças analisadas no corpus PRESEEA.

Traço de estatividade nos verbos das sentenças analisadas no corpus

Preseea

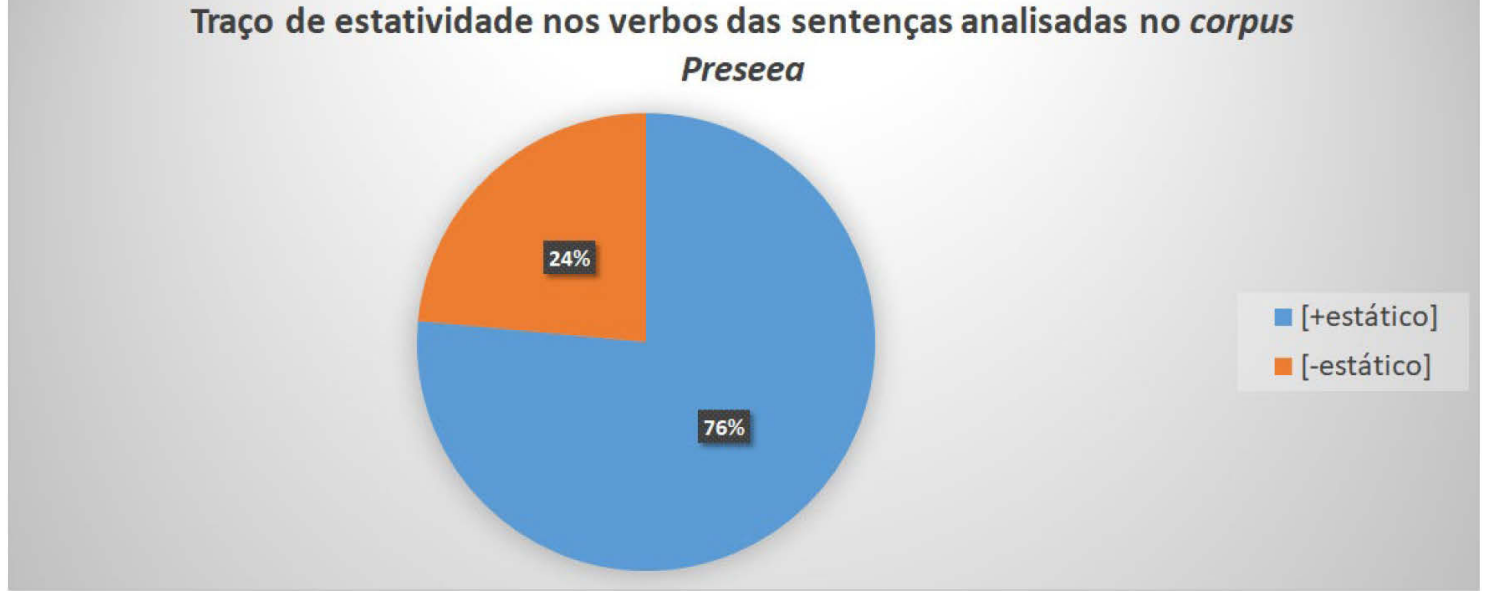

Fonte: elaborado pelos autores.

Com relação ao traço de duratividade, 49 verbos apresentavam o traço [+durativo] (98\%), enquanto 1 carregava o traço [-durativo] (2\%), como podemos ver no Gráfico 3 a seguir.

Gráfico 3 - Traço de duratividade nos verbos das sentenças analisadas no corpus PRESEEA.

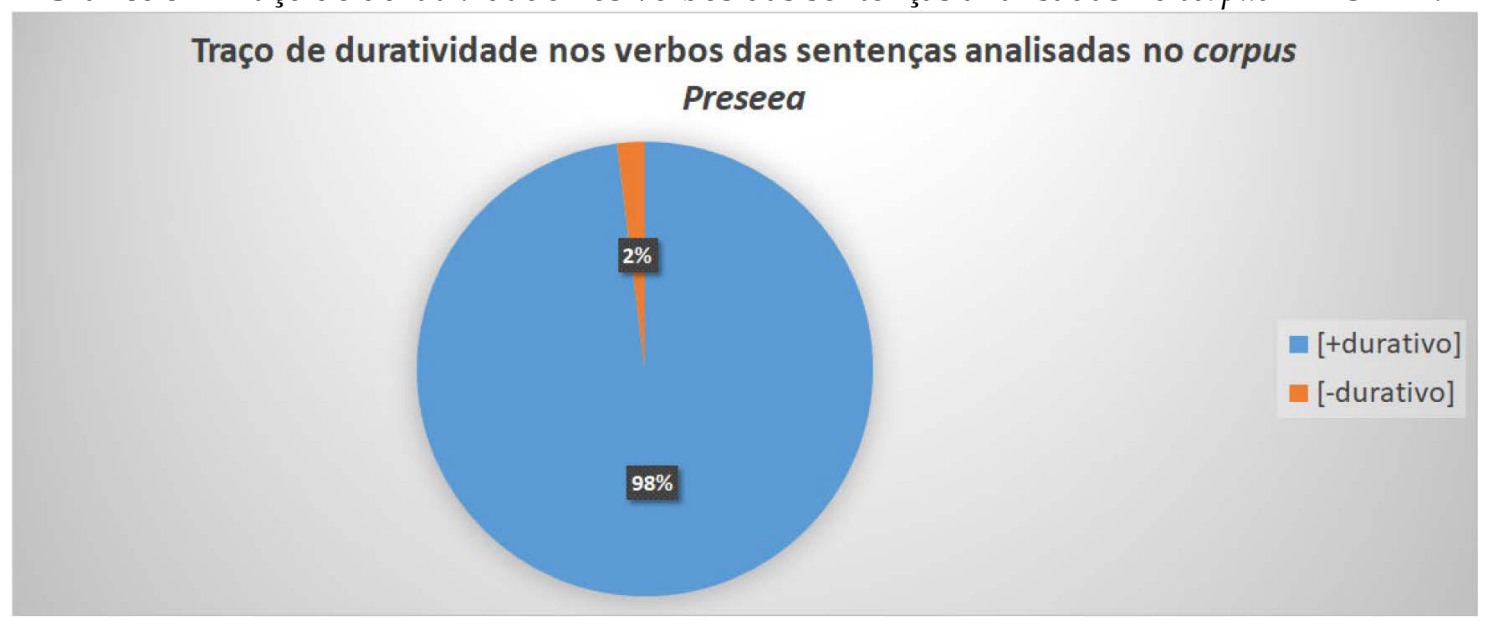

Fonte: elaborado pelos autores.

Com relação aos dados extraídos do corpus C-Oral, foram encontradas 42 ocorrências de determinantes plurais indefinidos introduzindo complementos verbais. Nesse caso, havia 27 ocorrências do determinante unos(as) (64\%), como no exemplo em (21); 12 com muchos(as) (29\%), como em (22); 2 com algunos(as) (5\%), como vemos em (23); e 1 com varios(as) (2\%), como em (24). 
(21) Les regalamos unos calzoncillos Calvin Klein.

'Presenteamos-lhes umas cuecas Calvin Klein.'

(22) (...) porque mamá me hace muchas comidas.

'(...) porque mamãe faz muitas comidas para mim.'

(23) Hay algunos juegos que son muy difíciles.

'Há alguns jogos que são muito difíceis.'

(24) Hay varias traducciones por ahí circulando.

'Há várias traduções por aí circulando.'

Assim como nos dados encontrados no PRESEEA, no C-Oral, também não houve nenhuma ocorrência do se télico combinado a verbos cujos complementos eram introduzidos por determinantes plurais indefinidos e, em nenhum dos casos analisados, os verbos das sentenças eram de ingestão.

Com relação à presença do traço de estatividade nos verbos das sentenças analisadas, observamos que 25 apresentavam o traço [+estático] (60\%), enquanto 17 carregavam o traço [-estático] (40\%), como apresentado no Gráfico 4.

Gráfico 4 - Traço de estatividade nos verbos das sentenças analisadas no corpus C-Oral.

Traço de estatividade nos verbos das sentenças analisadas no corpus c-Oral

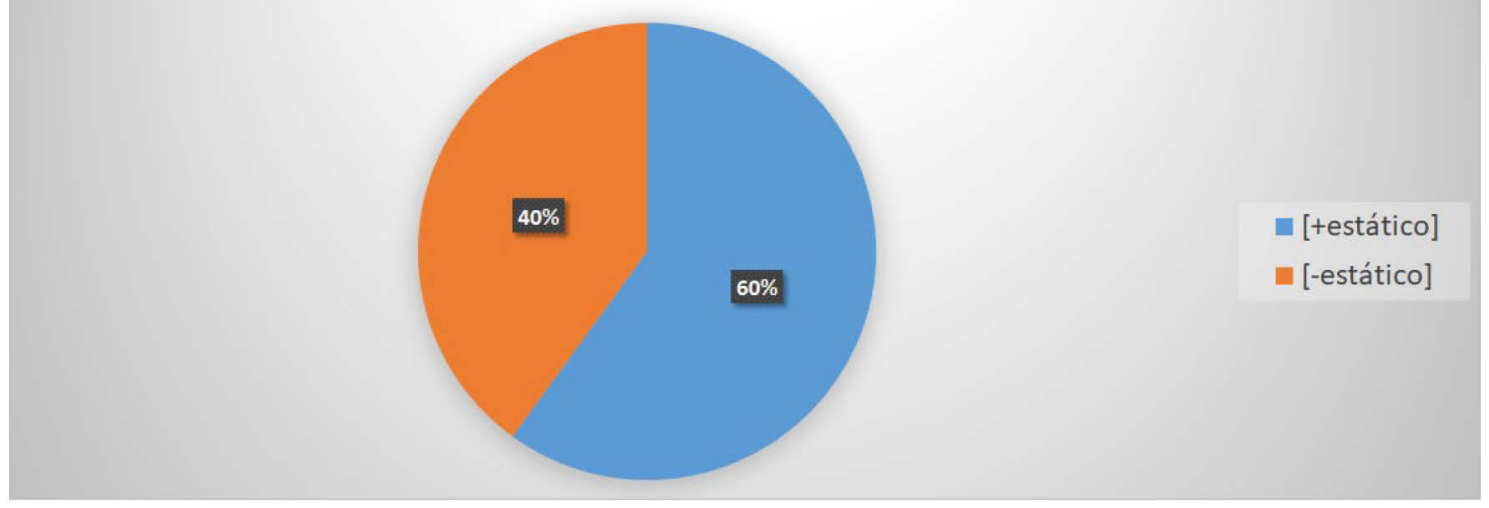

Fonte: elaborado pelos autores.

Com relação ao traço de duratividade, 39 verbos apresentavam o traço [+durativo] (93\%), enquanto 3 carregavam o traço [-durativo] (7\%), como se pode ver no Gráfico 5. 
Gráfico 5 - Traço de duratividade nos verbos das sentenças analisadas no corpus C-Oral.

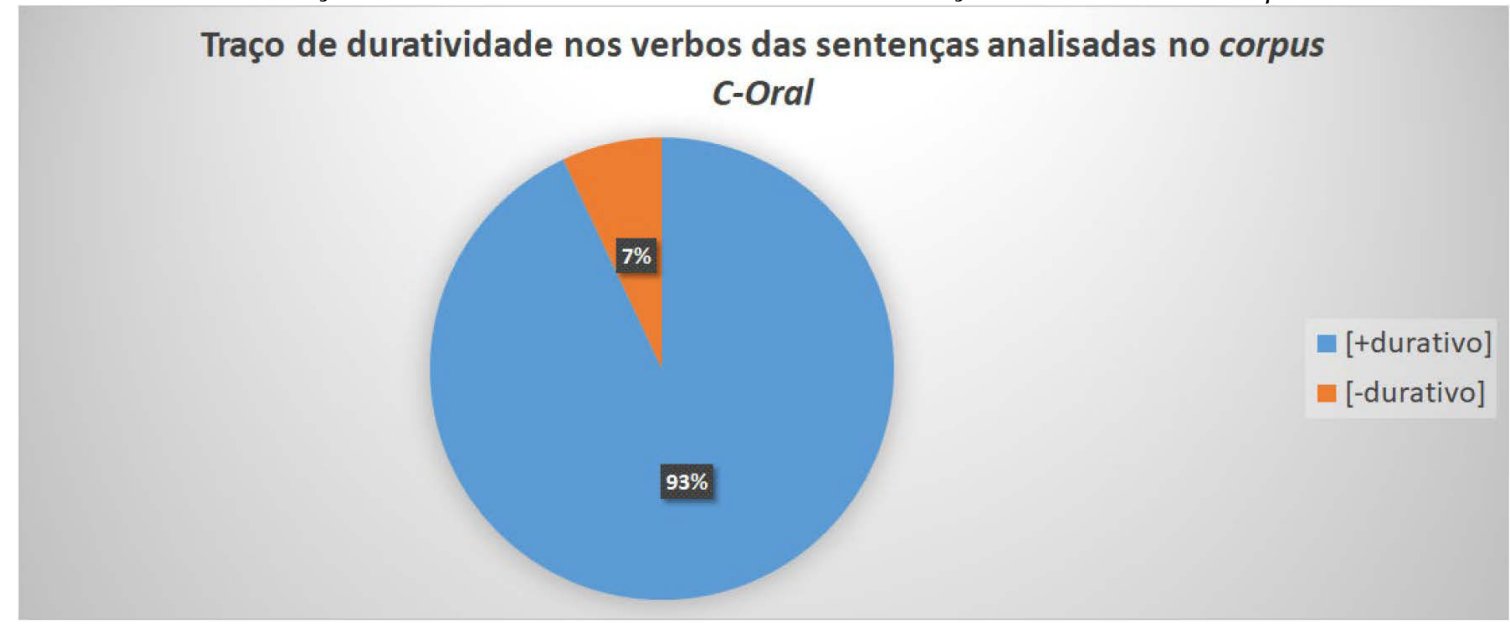

Fonte: elaborado pelos autores.

\section{Discussão}

Como visto na seção anterior, os resultados encontrados por meio da aplicação do teste linguístico e da análise dos corpora diferiram bastante. Se, por um lado, na aplicação do teste linguístico, a combinação de um verbo com um complemento introduzido por determinante plural indefinido com o se télico foi massivamente aceita pelos participantes, por outro lado, na análise de fala espontânea, não foi encontrada nenhuma ocorrência dessa combinação. Diante dessa grande disparidade, propomos duas possíveis interpretações para os dados obtidos neste estudo.

A primeira delas é a de que a diferença encontrada nos resultados pode ser proveniente de uma tendência à superaceitação de sentenças em contextos de teste. Nesse caso, poderíamos supor que os participantes aceitaram grande parte das sentenças porque estavam sendo avaliados por meio de um experimento que, possivelmente, não havia sido produzido por um falante nativo, o que aumentaria a tolerância desses sujeitos a sentenças que, na prática, não seriam produzidas por eles. Essa interpretação sustentaria a ideia de que a construção estudada não seria possível no castelhano setentrional peninsular, explicando sua ausência nos dados de fala espontânea. 
No entanto, a quantidade de sentenças consideradas gramaticais no teste realizado pelos participantes é extremamente alta e as únicas alterações foram feitas por um único participante e em apenas duas sentenças. Isso nos leva a crer que a grande aceitação de sentenças no teste seria um indicativo de que a construção analisada neste estudo é gramatical e não decorrente de uma mera superaceitação em contexto de teste. Dessa forma, a interpretação proposta no parágrafo anterior não parece plausível para a discussão dos resultados obtidos.

A segunda interpretação é a de que a combinação entre o se télico e verbos que contenham complementos introduzidos por determinantes plurais indefinidos é possível no castelhano setentrional peninsular. Nesse caso, podemos especular que as alterações efetuadas por um mesmo informante em duas sentenças-alvo do teste linguístico tenham sido motivadas pelo fato de, na gramática mental desse falante especificamente, a combinação estudada ser, de fato, pouco natural ou frequente.

A ausência da combinação estudada nas ocorrências encontradas por meio da análise dos corpora pode ser decorrente de dois fatores. O primeiro diz respeito à possibilidade de o se télico não ser frequentemente combinado a verbos com complementos introduzidos por determinantes plurais indefinidos na produção linguística dos falantes da variedade estudada. O segundo diz respeito à possibilidade de o recorte feito dos corpora analisados não ter favorecido a emergência dessa combinação.

É possível ainda que os contextos de fala construídos nas entrevistas e nas conversas informais não fomentassem o uso dessa estrutura, já que, por exemplo, nos dados analisados não houve qualquer produção de complemento introduzido por determinante plural indefinido de verbos de ingestão, aqueles que especialmente favorecem o uso do se télico (SANZ, 2000). Por outro lado, no teste de julgamento de gramaticalidade comentado, todas as sentenças-alvo continham verbos dessa natureza, o que pode ter contribuído para uma maior aceitação das sentenças. 
Outro fator, que pode explicar a ausência do se télico combinado a verbos cujos complementos fossem introduzidos por determinantes plurais indefinidos nas sentenças analisadas dos dados de fala espontânea, está relacionado às outras noções aspectuais semânticas presentes nos verbos dessas sentenças. Por exemplo, em 76\% das sentenças analisadas do PRESEEA e em $60 \%$ das sentenças analisadas do C-Oral, o verbo que continha um complemento introduzido por determinante plural indefinido carregava também o traço aspectual semântico [+estático].

Levando em consideração que a telicidade é incompatível com a estatividade (COMRIE, 1976; SMITH, 1991; SLABAKOVA, 2000; WACHOWICZ, 2008) e que o se télico não pode figurar em sentenças com verbos de estados (SANZ; LAKA, 2000; LOURENÇONI, 2017), podemos supor que esse fator explica a ausência da combinação analisada em mais da metade dos dados encontrados.

Outra noção aspectual semântica verificada nas sentenças analisadas nos corpora que pode ter desfavorecido a produção do se télico pode ter sido o traço aspectual semântico [-durativo] presente nos verbos dessas sentenças. Com relação a esse traço, 2\% das ocorrências no PRESEEA e 7\% das ocorrências no C-Oral possuíam o traço [-durativo], que, segundo Sanz e Laka (2000) e Lourençoni (2017), desfavorece o uso do se télico. Ainda que muitos dos outros verbos possuíssem o traço [+durativo], o que possibilitaria o uso dessa partícula aspectual, é preciso levar em consideração que muitos desses também carregavam o traço [+estático]. Dessa forma, nos restariam apenas $20 \%$ das ocorrências no PRESEEA e 30\% no C-Oral em que a presença do se télico não configuraria uma agramaticalidade: aquelas que apresentassem o traço [+durativo] e, ao mesmo tempo, o traço [-estático].

Com base no que se discorreu até aqui, parece-nos mais adequado, portanto, adotar a segunda interpretação dos dados. Logo, acredita-se na confiabilidade dos resultados obtidos por meio da aplicação do teste linguístico e no fato de que a ausência de se télico nos dados de fala espontânea é decorrente do recorte feito do 
material analisado, uma vez que, dentre as sentenças analisadas, não havia verbos de ingestão e que, em alguns casos, a presença do se télico não seria possível devido à incompatibilidade com outros traços aspectuais semânticos presentes nos verbos dessas sentenças.

Baseados na segunda interpretação dos resultados, concluímos que a combinação entre o se télico e os verbos cujos complementos sejam introduzidos por determinantes plurais indefinidos é possível no castelhano setentrional peninsular, refutando a hipótese deste estudo. Vale destacar que a refutação da hipótese foi possível especialmente com base nos resultados obtidos no teste de julgamento de gramaticalidade comentado.

Levando em consideração que a hipótese deste estudo foi refutada, podemos afirmar que as assunções de Suárez-Cepeda (2005) sobre a possibilidade de combinação do se télico com determinantes singulares e com determinantes plurais indefinidos parecia mais adequada. Além disso, parece que a proposta de Rothstein (2008) é corroborada por dados do castelhano setentrional peninsular, uma vez que determinantes plurais indefinidos, como unos(as), algunos(as), podem figurar em sentenças em que também esteja presente o se télico. Logo, conclui-se que a presença desses determinantes nos complementos verbais direcionam a uma leitura télica da sentença.

Tais dados parecem sustentar a discussão proposta por Rothstein (2008) de que os determinantes plurais indefinidos não devem ser interpretados como marcadores de ausência de delimitação, mas sim como indicadores do modo como o complemento é medido, sendo considerados, portanto, reveladores da expressão de uma quantidade. Logo, o fato de determinantes plurais indefinidos não serem capazes de apresentar uma medida precisa do complemento sobre o qual atuam e ainda assim poderem estar presentes em sentenças com o se télico nos leva a argumentar a favor 
da proposta de Rothstein (2008) e contra a proposta de Verkuyl (2002) segundo a qual uma quantificação genérica do complemento levaria a uma interpretação atélica.

Diante desta discussão, vale destacar que, no contínuo apresentado por Moure (1990) e representado na Figura 1 deste artigo, poderíamos inserir os determinantes plurais indefinidos mais à esquerda na linha, que representa a relação entre o grau de definição do complemento e o valor aspectual de telicidade, uma vez que esses determinantes são capazes de direcionar a uma leitura télica.

Levando em consideração que o valor aspectual de telicidade é depreendido dos diversos elementos que compõem uma sentença, como descrito na seção 2 deste artigo, acreditamos que este trabalho contribui para o entendimento dos fatores atuantes na composicionalidade aspectual de sentenças télicas. Uma vez que argumentamos que complementos verbais que possuam uma delimitação - ainda que não precisa quanto à quantidade - contribuam para o valor aspectual de telicidade e identificamos que a emergência do se télico nas construções investigadas parece ter sido amplamente desfavorecida por traços aspectuais semânticos dos verbos dessas construções, defendemos que os resultados deste estudo ilustram como diferentes elementos de uma sentença atuam em conjunto na veiculação da telicidade.

Por fim, se concebemos que complementos verbais introduzidos por determinantes plurais indefinidos levam a uma leitura télica da sentença, como argumentamos acima, podemos fazer também considerações sobre a nomenclatura utilizada por alguns autores para tratar do complemento capaz de delimitar um evento e, consequentemente, torná-lo télico.

Slabakova (2000) e Lourençoni (2014) nomeiam o complemento que leva à delimitação do evento como um "complemento de cardinalidade especificada". Se compreendermos "cardinalidade especificada" como quantificação precisa, seria necessário retirar de seu escopo os determinantes plurais indefinidos, pois apresentam uma medida imprecisa do complemento. Com base nos resultados deste estudo, 
podemos argumentar que tal nomenclatura parece ser inadequada para a descrição do fenômeno linguístico de telicidade.

A nomenclatura adotada por De Miguel (1999) para o complemento que figura em sentenças télicas - "complemento direto determinado" - também parece apresentar problemas, pois pode provocar uma interpretação equivocada do termo. Na Nueva gramática de la Lengua Española ${ }^{15}$, afirma-se que os artigos em espanhol podem ser classificados como definido/determinado ou indefinido/indeterminado.

Dessa forma, acreditamos que o termo "complemento direto determinado" pode levar ao entendimento de que apenas os artigos definidos (ou determinados), como el/la, e não os indefinidos (ou indeterminados), como un/una, podem direcionar a uma leitura télica. Os resultados de estudos que analisaram os contextos que ensejam o uso do se télico, bem como os dados apresentados neste trabalho, comprovam que artigos indefinidos podem também direcionar a essa leitura.

Diante disso, parece-nos mais adequado adotar o termo "complemento direto delimitado" como aquele que possibilita a delimitação do evento expresso pelo verbo, uma vez que não leva a crer que o complemento necessita apresentar uma medida precisa e não direciona à interpretação de que o complemento precisa ser introduzido por um artigo definido. O termo que propomos aqui parece dar mais clareza no tocante à delimitação do ponto final inerente da situação.

\section{Considerações finais}

Este trabalho tinha por objetivo investigar se o se télico, partícula que evidencia o valor aspectual de telicidade, na variedade do espanhol da Espanha conhecida como castelhano setentrional peninsular, poderia figurar em orações em que o verbo contivesse um complemento introduzido por um determinante plural indefinido. A

\footnotetext{
15 Tal documento pode ser considerado um dos principais para a descrição da língua espanhola, uma vez que é a adotada pela Real Academia Española.
} 
fim de atingir esse objetivo, foi aplicado um teste linguístico de gramaticalidade comentado e foi realizada uma análise de fala espontânea, coletada por meio de dados de dois corpora.

No teste linguístico, a combinação investigada foi considerada, em quase todos os casos, como gramatical pelos informantes. Por outro lado, nos dados de fala espontânea, não foi encontrada nenhuma ocorrência em que houvesse essa estrutura. Com base, principalmente, nos resultados obtidos pela aplicação do teste, refutamos a hipótese de que o se télico não se combinaria a verbos com complementos introduzidos por determinantes plurais indefinidos no castelhano setentrional peninsular.

Acreditamos, portanto, que o fato de não haver ocorrências dessa combinação nos corpora pode ser resultante da pouca frequência de uso dessa combinação na variedade investigada ou do recorte feito para análise, levando em consideração que os traços aspectuais semânticos presentes na maioria dos verbos das sentenças analisadas não eram compatíveis com o de telicidade.

Discutimos que determinantes plurais indefinidos podem direcionar a uma leitura télica da sentença. Dessa forma, os resultados deste trabalho parecem corroborar a proposta de Rothstein (2008), na qual se afirma que, para veicular o valor aspectual télico, é preciso que haja uma delimitação para o complemento, ainda que sua medida não seja necessariamente precisa.

Percebe-se, então, a necessidade de ampliar o escopo de análise dos dados, aumentando o número de horas de análise de fala espontânea a fim de buscar ocorrências da combinação estudada, o que pode ser revelador no entendimento da frequência de uso dessa construção. Além disso, a formulação de um teste online pode revelar se essa construção pode provocar alguma estranheza a falantes nativos do espanhol, sendo sua aceitabilidade decorrente de uma reinterpretação da sentença após seu processamento em tempo real, ou se essa construção é realmente plenamente aceitável e, portanto, gramatical. 
Faz-se necessário também investigar se outros determinantes plurais, como os definidos "los/las" e os que recebem uma intensidade, como "muchísimos", podem igualmente direcionar a uma leitura télica. Por fim, pretende-se ainda averiguar se a combinação analisada neste estudo é possível em outras variedades do espanhol.

\section{Referências bibliográficas}

BASSO, R. Telicidade e Detelicização. Revista Letras, Curitiba, no 72, p. 215-232, 2007. Disponível em: https://revistas.ufpr.br/letras/article/view/7542/10510. Acesso em: 19 jun. 2019. DOI https://doi.org/10.5380/rel.v72i0.7542

BERTINETTO, P. On a frequent misunderstanding in the temporal-aspectual domain: the perfective-telic confusion. In: CECCHETTO, C.; CHIERCHIA, G.; GAUSTI, M. (ed.). Semantic interfaces: reference, anaphora and aspect. Stanford: CSLI p. 177 - 210, 2001.

CASTILHO, A. T. Aspecto verbal no português falado. In: ABAURRE, M. B.; RODRIGUES, A. (org.). Gramática do português falado. Campinas: Ed. da Unicamp, v. 8. , 2003. p. 83-121.

COAN, M.; FEITAG, R.; PONTES, V. Aspecto Inerente: análise sociofuncional de formas verbais imperfectivas de passado em espanhol. SIGNUM: Estud. Ling., nº 16, v.2, p. 39-65, 2013. Disponível em: http://www.repositorio.ufc.br/bitstream/riufc/20198/1/2013 art mcoan.pdf. Acesso em 25 ago. 2019. DOI https://doi.org/10.5433/2237-4876.2013v16n2p39

CELERI, W. A composicionalidade aspectual revisitada. 2008. 99 f. Dissertação (Mestrado em Linguística) - Faculdade de Letras, Universidade Federal do Rio de Janeiro, Rio de Janeiro, 2008.

COMRIE, B. Aspect: an introduction to the study of verbal aspect and related problems. Cambridge: Cambridge University Press, 1976.

DAHL, O. Logic, Pragmatic and Grammar. Gotemborg: University of Göteborg, Departament of Linguistics, 1977.

DE MIGUEL, E. El aspecto léxico. In: BOSQUE, I.; DEMONTE, V. (ed.). Gramática descriptiva de la lengua española. Madrid: Espasa Calpe, 1999. p. 2977-3060. 
DE MIGUEL, E.; LAGUNILLA, M. F. El Operador Aspectual Se. Revista Española de Lingüística, v. 30, n. 1, p. 13-43, 2000. Disponível em: https://dialnet.unirioja.es/servlet/articulo?codigo=41379. Acesso em: 19 de jun. 2019.

DECLERCK, R. Aspect and bounded/unbounded (telic/atelic) distinction. Linguistics, London, $\mathrm{n}^{\mathrm{o}}$ 17, p. 761-794, 1979. Disponível em: https://www.researchgate.net/publication/243647038 Aspect and the BoundedUnb ounded TelicAtelic Distinction. Acesso em: 19 jun. 2019. DOI https://doi.org/10.1515/ling.1979.17.9-10.761

FREITAG, R. Aspecto inerente e passado imperfectivo no português: atuação dos princípios da persistência e da marcação. Alfa, nº 55, v. 2, p. 477-500. 2011. Disponível em: http://www.scielo.br/pdf/alfa/v55n2/06.pdf. Acesso em: 25 ago. 2019. DOI https://doi.org/10.1590/S1981-57942011000200006

GAREY, H. Verbal Aspect in French. In: Language, no 33, p. 91-110, 1975. Disponível em: https://user.phil-fak.uni-duesseldorf.de/ filip/Garey.1957.pdf. Acesso em: 19 jun. 2019. DOI https://doi.org/10.2307/410722

GOMES, J. Telicidade e sua compatibilidade com expressões adverbiais durativas no espanhol. 2017. 38 f. Monografia (Graduação em Letras Português - Espanhol) Faculdade de Letras, Universidade Federal do Rio de Janeiro, Rio de Janeiro, 2017.

LESSA, A. A composicionalidade do aspecto em tempo passado e no espanhol. In: Jornada Massarani de iniciação científica, artística e cultural da UFRJ, 29, 2017, Rio de Janeiro: UFRJ, 2007. 1 CD.

LÓPEZ, C. Las construcciones con se: estado de la cuestión. In: LÓPEZ, C. Las construcciones con se. Madrid: Visor Libros, 2002. p. 18-167.

LOURENÇONI, D. O traço de telicidade e suas realizações no português do Brasil e no espanhol do Chile. 2014. 52 f. Monografia (Graduação em Letras Português Espanhol) - Faculdade de Letras, Universidade Federal do Rio de Janeiro, Rio de Janeiro, 2014.

LOURENÇONI, D. Telicidade e sua realização pelo operador aspectual se no espanhol. 2017. 138 f. Dissertação (Mestrado em Linguística) - Faculdade de Letras, Universidade Federal do Rio de Janeiro, Rio de Janeiro, 2017.

LOURENÇONI, D.; MARTINS, A. O traço aspectual de telicidade e suas realizações no português do Brasil e no espanhol do Chile. SEDA - Revista de Letras da Rural/RJ, 
v. 1, n. 2, p. 5-28, 2016. Disponível em: http://www.ufrrj.br/SEER/index.php?journal=SEDA\&page=article\&op=view\&path\% 5B\%5D=2181. Acesso em: 22 de out. de 2019.

MARTINS, A.; GOMES, J.; LOURENÇONI, D. Telicidade e expressões adverbiais durativas no espanhol da Espanha: uma análise a partir do se télico. Caderno de squibs: temas em estudos formais da linguagem, v. 3, n. 1, p. 1-15, 2017. Disponível em: http://periodicos.unb.br/index.php/cs/article/view/20331. Acesso em: 22 out. 2019.

MORENO-FERNÁNDEZ, F.; ROTH, J. O. Atlas de la lengua española en el mundo. Madrid: Fundación Telefónica, 2007.

MOURE, T. El contenido aspectual telicidad en las cláusulas biactanciales del español. In: Verba, n. 18, p. 353-374, 1990. Disponível em: https://minerva.usc.es/xmlui/handle/10347/3161. Acesso em: 19 jun. 2019.

PATO, E. La sustitución de "cantara/cantase" por "cantaría/cantaba" en el castellano septentrional peninsular. Tesis Universidad Autónoma de Madrid, 2004.

PRESEEA (2014-): Corpus del Proyecto para el estudio sociolingüístico del español de España y de América. Alcalá de Henares: Universidad de Alcalá. [http://preseea.linguas.net]. Acesso em: 19 jun. 2019.

ROTHSTEIN, S. Theoretical and crosslinguistic approaches to the semantics of aspect. Amsterdam: Benjamins, 2008. DOI https://doi.org/10.1075/la.110

SANZ, M. Events and predication: a new approach to syntactic processing in English and Spanish. Amsterdam: John Benjamins B. V., 2000. DOI https://doi.org/10.1075/cilt.207

SANZ, M. LAKA, I. Oraciones transitivas con se: El modo de acción en la sintaxis. In: Las construcciones con se. Madrid: Visor Libros, 2002. p. 309-336.

SLABAKOVA, R. L1 Transfer revisited the L2 Acquisition of telicity marking in English by Spanish and Bulgarian native speakers. Linguistics, no 38-4, p. 739-770, 2000. DOI https://doi.org/10.1515/ling.2000.004.

SMITH, C. The Parameter of Aspect. Dordrecht: Kluwer Academic Publishers, 1991.

SUÁREZ CEPEDA, S. Pedro comió la torta vs. Pedro se comió la torta: L2 Acquisition of Spanish Telic se constructions. Anuario no 7 - Fac. de Cs. Humanas - UNLPam, p. 
277-295,

2005.

Disponível

em:

https://www.academia.edu/626852/Pedro Comi\%C3\%B3 La Torta Vs. Pedro Se C omi $\%$ C3\%B3 La Torta L2 Acquisition of Spanish Telic Se Constructions. Acesso em: 19 jun. 2019.

VENDLER, Z. Verbs and times. In: VENDLER, Z. (ed.). Linguistics in Philosophy. Ithaca: Cornell University Press. 1967. p. 97-121.

VERKUYL, H. Aspectual composition: surveying the ingredients. In: VERKUYL, H.; SWART, H.; VAN HOUT, A. Perspectives on aspect. 1aㅡ ed. Springer., 2002. p. 19-39. DOI https://doi.org/10.1007/1-4020-3232-3_2

WACHOWICZ, T. C. As leituras aspectuais da forma do progressivo do português brasileiro. 2003. 221 f. Tese (Doutorado em Linguística) - Faculdade de Filosofia, Letras e Ciências Humanas, Universidade de São Paulo, São Paulo, 2003.

WACHOWICZ, T. C. Telicidade e classes aspectuais. Revista do Gel, v. 5, n. 1, p. 5768, 2008. Disponível em : https://revistadogel.emnuvens.com.br/rg/article/view/133/0 Acesso em: 25 ago. 2019. 